\title{
Addressing Child Health Inequity Through Case Management of Under-Five Malaria in Nigeria: An Extended Cost- Effectiveness Analysis
}

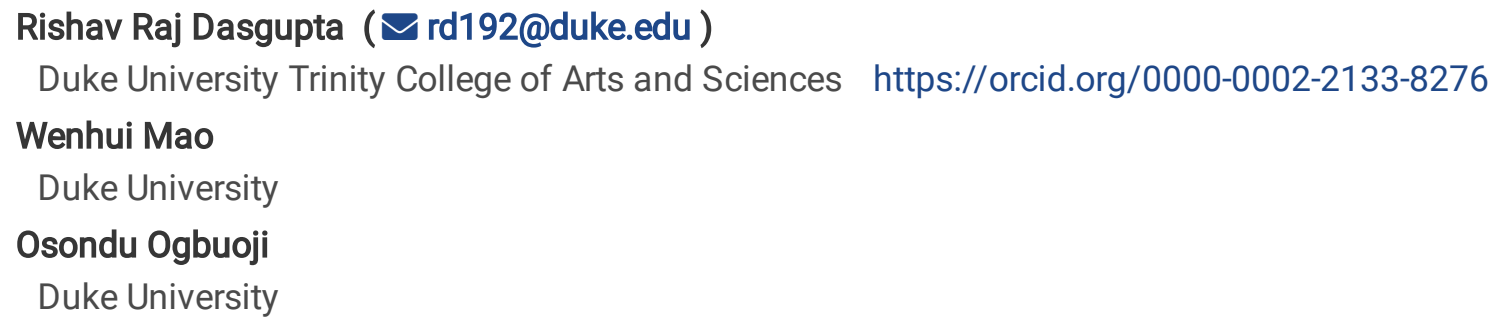

\section{Research}

Keywords: child health inequality, decision-tree model, out-of-pocket expenditure, catastrophic health expenditure, financial risk protection

Posted Date: May 24th, 2021

DOI: https://doi.org/10.21203/rs.3.rs-537585/v1

License: @ (i) This work is licensed under a Creative Commons Attribution 4.0 International License. Read Full License

Version of Record: A version of this preprint was published at Malaria Journal on March 9th, 2022. See the published version at https://doi.org/10.1186/s12936-022-04113-w. 


\section{Abstract}

\section{Background}

Under-five malaria in Nigeria is a leading cause of global child mortality, accounting for 95,000 annual child deaths. This is largely due to high out-of-pocket medical expenditure, which discourages care-seeking and use of effective antimalarials in the poorest households. Resultingly, Nigeria has some of the worst indicators of child health equity in the world, stressing the need to evaluate the outcomes of potential interventions across socioeconomic lines.

\section{Methods}

Using a decision tree model, we conducted an extended cost-effectiveness analysis of subsidies covering the direct and indirect costs of case management of under-five malaria in Nigeria. We estimated the number of child deaths averted, outof-pocket (OOP) expenditure averted, cases of catastrophic health expenditure (CHE) averted, and cost of implementation. We assumed pro-poor increase in treatment uptake, as the malaria burden in Nigeria disproportionately affects the poor.

\section{Findings}

Fully subsidizing direct medical costs and instating a voucher system covering non-medical and indirect costs would annually avert over 19,000 under-five deaths, 8,600 cases of CHE, and US\$205.2 million in OOP spending. Per US\$1 million invested, this corresponds to an annual reduction of 76 under-five deaths, 34 cases of CHE, and over US\$800,000 in 00P expenditure. On account of low initial treatment coverage in poorer socioeconomic groups, health and financial-risk protection benefits would be pro-poor, with the poorest $40 \%$ of Nigerians accounting for $72 \%$ of all deaths averted, $55 \%$ of all OOP expenditure averted, and $74 \%$ of all cases of CHE averted. Subsidies targeted to the poor would see greater benefits per dollar spent than broad, non-targeted subsidies.

\section{Conclusion}

Subsidizing case management of under-five malaria for the poorest and most vulnerable would reduce illness-related impoverishment and child mortality in Nigeria while preserving limited financial resources. This study is an example of how focusing a targeted policy-intervention on a single, high-burden disease can yield large health and financial-risk protection benefits in a low and middle-income country context and address equity consideration in evidence-informed policymaking.

\section{Introduction}

Despite significant progress in global malaria control over the last two decades, malaria remains one of the leading causes of morbidity and mortality in children under the age of five, who account for two-thirds of the global malaria burden [1-2]. Recent trends also indicate that progress in malaria control is slowing in the highest burden countries [3]. In Nigeria, which bears $25 \%$ of global morbidity, malaria annually accounts for an estimated $60 \%$ of outpatient hospital visits, 50 million cases, and 100,000 deaths [4-6]. The most vulnerable Nigerians are under-five children, who experience an average of 2-4 episodes per year and account for as much as $90 \%$ of national malaria mortality $[7,8]$. Resultingly, as much as $36 \%$ of under-five mortality in Nigeria is attributable to malaria $[9,10]$.

While prompt and effective treatment of malaria has good clinical outcomes in under-fives, cases where treatment is absent, delayed, or ineffective can become severe and lead to life-threatening complications [7]. Nigeria's high under-five malaria mortality is largely attributable to a health financing system that leaves many individuals uninsured, resulting in high out-of-pocket (OOP) medical expenditure that discourages care-seeking behavior, especially among the poor (Box 1) [11]. Nigeria has one of the lowest rates of care-seeking for suspected cases of under-five malaria in the world, with just under $20 \%$ of all under-fives with fever being brought to health facilities for clinical consultation and parasitological testing [1]. 
Even when care is sought, the most effective malaria treatments are prohibitively costly and used by few Nigerians [12, 13]. Artemisinin-based combination therapy (ACT), the WHO-recommended first line of treatment for uncomplicated malaria, is $98 \%$ effective in producing adequate parasitological and clinical response (APCR) necessary for a child to be cured but is up to twenty times more costly than significantly less effective monotherapies such as chloroquine and sulphadoxinepyrimethamine [14, 15]. On account of high cost to individuals, ACTs are used to treat only $40 \%$ of under-five malaria cases in Nigeria [16]. Financial barriers especially hurt the poorest and most vulnerable Nigerians, who use ACT at about half the rate of the richest [16].

Prior studies of countries in Sub-Saharan African have demonstrated that appropriate diagnosis and treatment are costeffective interventions for case management of under-five malaria, but there are knowledge gaps regarding the costeffectiveness of such interventions in Nigeria in particular, as well as how equitable such interventions would be [26]. Equity consideration in evidence-informed policymaking will be crucial to improving child health outcomes in Nigeria-with an exceptionally high under-five mortality rate amongst its poorest children ( $14 \%$ vs. $5 \%$ for the poorest and richest fifth, respectively), child health equity is among Nigeria's most pressing public health challenges $[27,28,29]$.

This study estimates the potential health and economic benefits of publicly financing case management of under-five malaria in Nigeria through the provision of government subsidies. Particularly, we apply extended cost effectiveness analysis (ECEA) to estimate intervention benefits across different socioeconomic groups. To account for constraints in government health budgets, we investigate the effects of multiple financing strategies that offer varying levels of coverage [30]. ECEA is an analytical technique that assesses health interventions across two main dimensions: health gains and financial risk protection afforded [31]. Moreover, ECEA disaggregates the effects of interventions across population strata of interest, allowing policymakers to identify which subgroups within a broader target population would benefit most from an intervention [31]. This study adds new value to existing cost-effectiveness research by for the first time investigating how the health and economic benefits of any malaria intervention would be distributed across socioeconomic lines in Nigeria, with the goal of informing policymakers in creating targeted, cost-effective interventions that help the most vulnerable people while preserving limited financial resources [32].

\section{Box 1: The financial landscape of malaria treatment in Nigeria}

In observance of the United Nations Millennium Development Goals (MDGs) for 2000-2015, which aimed in part to eradicate poverty and reduce child mortality, Nigeria's National Health Insurance Scheme piloted the Free Maternal and Child Health Program (FMCHP) in 2009 [17,18]. Among other services, the FMCHP provided free malaria treatment to underfive children brought to public health facilities in 12 out of 36 states [18,19]. Introduction of the FMCHP coincided with national reductions in child mortality, indicating potential efficacy of the program [18]. However, the FMCHP ended in 2015 with the conclusion of the MDGs, as states were unable to sustain necessary funding [18]. As a result, most Nigerian's currently pay for malaria treatment out of pocket (OOP) [10].

The OOP cost of treating under-five malaria accounts for nearly half of all household medical expense in Nigeria, significantly contributing to catastrophic health expenditure (CHE) in the poorest households [20]. Generally defined as medical expenditure exceeding $10 \%$ of annual income, $\mathrm{CHE}$ not only leaves individuals unable to pay for future essential health services but often leads to cycles of poverty [21,22]. Globally, CHE pushes nearly 100 million people into poverty per year, exacerbating child health inequalities. Offering financial risk protection, or protection against illness-related impoverishment resulting from CHE, will be essential to make progress toward several of the WHO's Sustainable Development Goals (SDGs) for 2016-2030 [23].

To that end, scaling up programs like the FMCHP for the provision of effective malaria treatment could incentivize careseeking behavior and increase service use of the most effective therapies, which may have a positive, pro-poor impact on

Page $3 / 20$ 
child health in Nigeria $[19,23,24]$. Such an intervention would contribute progress toward several SDGs, namely SDG 1 (reducing poverty), SDG 3 (ensuring good health and well-being at all ages), and SDG 10 (reducing inequality within societies) [1,24]. Financing under-five malaria treatment through government subsidies would also offer protection against a major source of CHE in Nigeria, which will help achieve SDG target 3.8: achieving Universal Health Coverage (UHC) that ensures access to essential health-care services and access to safe, effective, quality and affordable essential medicines for all $[24,25]$.

\section{Methods}

We conducted an extended cost-effectiveness analysis (ECEA) using a decision tree model created with TreeAge Pro Healthcare software, Version 2020 R2. Using demographic and epidemiological data from published literature and unpublished costing data as parameters, we quantified the health and economic effects of three different intervention scenarios over a year of implementation, disaggregated across five wealth quintiles (Q1-Q5 in ascending order of wealth index). The intervention outcomes estimated were the number of under-five deaths averted, OOP expenditure averted, cases of catastrophic health expenditure (CHE) averted, and the cost of implementation.

\section{Interventions}

Case management of under-five malaria incurs direct medical costs (consultation, appropriate diagnosis, medical supplies, drugs), direct non-medical costs (food on the way to the health facility, transportation, other non-medical supplies and services), and indirect costs (income forgone in productive time lost to caregiving) [33,34,35]. Non-medical and indirect costs often represent a high proportion of total expense associated with case management, especially for severe cases requiring inpatient hospitalization and significant time spent away from work for caregiving $[19,36]$.

While the FMCHP subsidized direct medical costs of treatment, off-setting non-medical and indirect costs will more effectively mitigate the economic burden of treating under-five malaria and could further incentivize service use of effective treatment [19]. To consider variable financing capacity, we modeled three intervention scenarios: (1) a 50\% subsidy of direct medical costs (50\% DMC), (2) a full subsidy of direct medical costs (full DMC), and (3) a full subsidy of direct medical costs in addition to compensating individuals for non-medical and indirect costs through a voucher system (full DMC $+\mathrm{NMC}+\mathrm{IC}$ ).

We assumed higher increase in treatment coverage for the interventions covering a greater proportion of total costs, as they are likely to incentivize better care-seeking behavior [37]. We also assumed relatively higher increase in treatment coverage in poorer quintiles, based on findings indicating that FMCHP clinics were disproportionately serviced by poorer and more disease-burdened socioeconomic groups [18]. Respectively per quintile, we modelled a 2.5, 2, 1.5, 1, and 0.5 percentage point increase in treatment coverage for the 50\% DMC subsidy; a 5, 4, 3, 2, and 1 percentage point increase in treatment coverage for the full DMC subsidy; and a 10, 8, 6, 4, and 2 percent percentage point increase in treatment coverage for the full DMC + NMC + IC subsidy.

\section{Model parameters}

Parameters were disaggregated by wealth quintile using empirical data from the 2018 Nigeria Demographic and Health Survey (DHS) when possible and estimated when disaggregated data were not available (Table 1) [16]. Calculations for estimating select model parameters by quintile are described in detail in Additional file 1 Section I. Estimated parameters were calibrated so our model accurately estimated the reported number of annual under-five malaria deaths in Nigeria in a base case scenario.

\section{Model Flow}

Using TreeAge Pro Healthcare decision analysis software, we created one tree for each wealth quintile (Q1-Q5, in ascending order of wealth). Each decision tree is identical in structure, but parameter values differ based on wealth quintile. The entry 
point for each tree is a case of under-five malaria. Annual cases of under-five malaria per quintile were estimated using data from the 2019 World Malaria Report, the U.S. President's Malaria Initiative Nigeria Malaria Operational Plan for 2020, and the 2018 Nigeria DHS $[1,16,38]$.

The model's first chance node splits into clinically treated and untreated cases (Fig. 1A). The probability that a case is clinically treated was proxied by the proportion of febrile under-fives for whom treatment is sought, available from the 2018 Nigeria DHS. This approximation was based on the fact that fever in under-fives is a relatively good indicator of malaria in endemic countries [39]. Treated cases split into those treated with ACTs and without ACTs (e.g., chloroquine, sulphadoxinepyrimethamine), since ACT is the recommended standard first-line treatment but not always used. As the efficacy of ACT is highly dependent on adherence to treatment course, cases treated with ACT split into those both with and without proper adherence [40].

Both adherent and non-adherent cases were split into treatment success (defined as adequate parasitological and clinical response-i.e., clearance of parasitemia) and treatment failure. Cases treated with non-ACTs were split directly into treatment success and failure on account of low overall treatment success of non-ACTs [41]. Treatment success results in a green terminal node representing survival (nodes 8,16 , and 24).

The orange nodes labeled Node 1, 9, 17, and 25 represent untreated cases or treatment failure; accordingly, these nodes branch into trees modeling progression to severe disease (Fig. 1B). The trees emanating from nodes 1, 9, 17 and 25 are identical in structure but have parametric differences according to the specific therapeutic scenario, discussed in more detail in Additional file 1 Section II. Node 1 is displayed in Fig. 1B, initially splitting into cases that remain uncomplicated or progress to severe. Uncomplicated cases split into survival and death, respectively resulting in terminal nodes 2 (green) and 3 (red). Severe cases split into cases that are treated and untreated. It was assumed that probability of seeking treatment for severe cases that were initially untreated was the same as the probability of initially seeking treatment for uncomplicated cases. Treated and untreated cases each split into survival and death, resulting in terminal nodes 4, 5, 6 and 7.

Using the TreeAge cost-effectiveness setting, cost and effectiveness values were assigned at all terminal nodes. Nodes representing survival and death were respectively assigned effectiveness values of 1 and 0 . For each scenario, OOP costs were assigned in 2020 United States Dollars (USD). Uncomplicated and severe cases were respectively assumed to incur outpatient and inpatient costs, a standard assumption in malaria modelling studies [22].

For example, terminal node 24, which corresponds to uncomplicated cases treated with ACT, was assigned a total case cost that included outpatient direct medical costs, non-medical costs, and indirect costs (Fig. 1A). Terminal node 2, corresponding to untreated uncomplicated cases, was assigned no OOP cost (Fig. 1B). Terminal node 4, corresponding to cases that were initially untreated but treated upon progressing to severe, was assigned a total case cost that included inpatient direct medical costs, non-medical costs, and indirect costs. Costing assignments for all terminal nodes are described fully in Additional file 1 Section II.

For the 50\% DMC intervention, direct medical costs were set at 50\% of base case values. For the full DMC intervention, direct medical costs were set at 0 . For the full DMC + NMC + IC intervention, all costs were set at 0 . About 23 million annual cases under-five cases were simulated across quintiles, a number corroborated by prior malaria modeling studies in Nigeria and data from the Institute of Health Metrics and Evaluation (IHME) Global Burden of Disease database [6, 42]. For each modeled scenario (base case plus three interventions), surviving cases and annual OOP expenditure were generated stochastically with Monte Carlo simulations using the TreeAge microsimulation tool. For intervention scenarios, increased coverage was simulated by increasing treatment probability at the first chance node (Fig. 1). OOP expenditure and surviving cases per intervention were compared against the outcomes of the base case scenario in which treatment coverage rates were set as the status quo and no subsidy was applied to treatment costs. Additionally, we compared the incremental OOP expenditure averted between each intervention scenario.

Page 5/20 
Individual cases of catastrophic health expenditure (CHE) were estimated using a simple disease model, described in Additional file 1 Section IV [31]. Cases of CHE were calculated using a threshold of $10 \%$ of annual per capita income, and CHE attributable to outpatient and inpatient care were estimated separately.

\section{Cost of Implementation}

For each intervention, the government cost of implementation was estimated using the same decision tree that was used to model deaths and OOP expenditure, but costing parameters were changed to reflect government costs [22]. In Nigeria, OOP spending represents $76 \%$ of total current health expenditure while government spending represents $24 \%$ [43]. The cost of implementing each intervention we modelled was estimated accordingly.

For the full DMC intervention, where the total direct medical costs of treatment are fully subsidized, the government cost of implementation per case was estimated by dividing the OOP direct medical cost per case by $76 \%$. For the $50 \%$ DMC intervention, the government cost of implementation per case was set as $50 \%$ of this value. For the full DMC + NMC + IC intervention, the government cost of implementation per case was set as the sum of total direct medical costs per case (i.e., OOP cost divided by 76\%) plus OOP non-medical and indirect costs per case. See Table 1 for estimated government costs per case.

\section{Sensitivity analysis}

Uncertainty in model outcomes (deaths, OOP expenditure, and $\mathrm{CHE}$ averted) was quantified using univariate sensitivity analysis. Each model parameter was changed to reflect a high value and low value scenario (respectively $20 \%$ higher and $20 \%$ lower than the base value). The relative impact of parameter variability was quantified by taking the percent difference between the model outcomes of high value scenarios and base value scenarios and doing the same for low value scenarios and base value scenarios. Uncertainty was estimated for broad intervention effects across all quintiles, averaged across all intervention scenarios unless otherwise noted in results. 
Table 1

Summary of model parameters for ECEA

\begin{tabular}{|c|c|c|c|}
\hline & Parameter & Value (Q1-Q5) & References and Notes \\
\hline Demographics & $\begin{array}{l}\text { Number of under-five children in } \\
\text { Nigeria }\end{array}$ & $\begin{array}{l}8822526 \\
7737789 \\
6436105 \\
5806958 \\
5185042\end{array}$ & $\begin{array}{l}\text { Authors' calculation using national } \\
\text { population size, median household size, and } \\
\text { number of under-fives per households from } \\
{[16] \text {. }}\end{array}$ \\
\hline \multirow[t]{10}{*}{ Epidemiology } & $\begin{array}{l}\text { Annual cases of under-five } \\
\text { malaria in Nigeria }\end{array}$ & $\begin{array}{l}\text { 6960185, } \\
6468963 \\
5261275 \\
3361056 \\
1318521\end{array}$ & $\begin{array}{l}\text { Authors' calculation using prevalence data } \\
\text { from [16]. }\end{array}$ \\
\hline & $\begin{array}{l}\text { Cumulative annual incidence of } \\
\text { uncomplicated under-five malaria } \\
(\%)\end{array}$ & $\begin{array}{l}77.1,81.9 \\
80.2,57.0 \\
25.2\end{array}$ & $\begin{array}{l}\text { Authors' calculation using treatment-seeking } \\
\text { behavior and probability of disease } \\
\text { progression to severe from [16]. and [52]. }\end{array}$ \\
\hline & $\begin{array}{l}\text { Cumulative annual incidence of } \\
\text { severe under-five malaria (\%) }\end{array}$ & $\begin{array}{l}1.8,1.7,1.6 \\
0.8,0.3\end{array}$ & $\begin{array}{l}\text { Authors' calculation using treatment-seeking } \\
\text { behavior and probability of disease } \\
\text { progression to severe from [16]. and [52]. }\end{array}$ \\
\hline & Treatment sought (\%) & $\begin{array}{l}\text { 67.8, 70.4, } \\
72.4,79.1 \\
85.2\end{array}$ & [16]. \\
\hline & $\begin{array}{l}\text { Treatment coverage increase for } \\
50 \% \text { DMC subsidy (percentage } \\
\text { point) }\end{array}$ & $\begin{array}{l}2.5,2,1.5,1 \\
0.5\end{array}$ & Authors' assumption \\
\hline & $\begin{array}{l}\text { Treatment coverage increase for } \\
\text { full DMC subsidy (percentage } \\
\text { point) }\end{array}$ & $5,4,3,2,1$ & Authors' assumption \\
\hline & $\begin{array}{l}\text { Treatment coverage increase for } \\
\text { full DMC + NMC + IC subsidy } \\
\text { (percentage point) }\end{array}$ & $10,8,6,4,2$ & Authors' assumption \\
\hline & $\begin{array}{l}\text { ACT used given treatment was } \\
\text { sought (\%) }\end{array}$ & $\begin{array}{l}46.6,51.5 \\
52.5,53.1,61\end{array}$ & [16]. \\
\hline & $\begin{array}{l}\text { Complicated malaria as } \\
\text { proportion of all cases }(\%)\end{array}$ & 2 & Authors' estimate using [38]. \\
\hline & $\begin{array}{l}\text { Uncomplicated malaria as a } \\
\text { proportion of all cases }(\%)\end{array}$ & 98 & Authors' estimate using [38]. \\
\hline \multirow[t]{5}{*}{ Treatment } & ACT efficacy (\%) & 98.3 & [14]. \\
\hline & $\begin{array}{l}\text { Adherence to treatment for } \\
\text { uncomplicated cases (\%) }\end{array}$ & $\begin{array}{l}66,71,76,81 \\
86\end{array}$ & $\begin{array}{l}\text { Authors' assumption using overall estimate } \\
\text { of adherence across all wealth indices from } \\
\text { [40]. }\end{array}$ \\
\hline & $\begin{array}{l}\text { Efficacy of ACT for } \\
\text { uncomplicated cases given non- } \\
\text { adherence as a proportion of } \\
\text { theoretical efficacy }(\%)\end{array}$ & 94.7 & [53]. \\
\hline & Non-ACT efficacy (\%) & 63 & $\begin{array}{l}\text { Authors' calculation using efficacy of } \\
\text { chloroquine and all other non-ACTs from [6]. }\end{array}$ \\
\hline & $\begin{array}{l}\text { Probability that untreated case } \\
\text { progresses to severe (\%) }\end{array}$ & 7 & Calibrated with low estimates from [52]. \\
\hline
\end{tabular}




\begin{tabular}{|c|c|c|c|}
\hline & Parameter & Value (Q1-Q5) & References and Notes \\
\hline & $\begin{array}{l}\text { Probability that treatment failure } \\
\text { progresses to severe (\%) }\end{array}$ & 2 & [54]. \\
\hline & $\begin{array}{l}\text { CFR of untreated severe malaria } \\
(\%)\end{array}$ & 45 & Calibrated with low estimates from [51]. \\
\hline & CFR of treated severe malaria (\%) & 4.9 & [55]. \\
\hline & $\begin{array}{l}\text { CFR of untreated uncomplicated } \\
\text { malaria }(\%)\end{array}$ & 0.1 & Authors' assumption based on [56]. \\
\hline \multirow[t]{12}{*}{$\begin{array}{l}\text { Costing (2020 } \\
\text { SUS) }\end{array}$} & $\begin{array}{l}\text { Outpatient OOP direct medical } \\
\text { costs per case, ACTs used }\end{array}$ & 7.98 & $\begin{array}{l}\text { Authors' calculation using forthcoming data } \\
\text { from multi-facility Duke costing study (see } \\
\text { Additional file } 1 \text { Section I, table 8) }\end{array}$ \\
\hline & $\begin{array}{l}\text { Outpatient OOP direct medical } \\
\text { costs per case, non-ACTs used }\end{array}$ & 6.29 & $\begin{array}{l}\text { Authors' calculation using [6]. and } \\
\text { forthcoming data from multi-facility Duke } \\
\text { costing study (see Additional file } 1 \text { Section I, } \\
\text { tables } 8 \text { and 9) }\end{array}$ \\
\hline & $\begin{array}{l}\text { Outpatient OOP direct non- } \\
\text { medical costs per case }\end{array}$ & 2.26 & $\begin{array}{l}\text { Authors' calculation using forthcoming data } \\
\text { from multi-facility Duke costing study (see } \\
\text { Additional file } 1 \text { Section I, table 10) }\end{array}$ \\
\hline & $\begin{array}{l}\text { Outpatient OOP indirect costs per } \\
\text { case }\end{array}$ & $\begin{array}{l}0.49,0.78 \\
1.14,1.70 \\
3.16\end{array}$ & $\begin{array}{l}\text { Authors' calculation using data on daily } \\
\text { consumption and days spent caregiving from } \\
\text { [57]. }\end{array}$ \\
\hline & $\begin{array}{l}\text { Inpatient OOP direct medical } \\
\text { costs per case }\end{array}$ & 39.25 & $\begin{array}{l}\text { Authors' calculation using forthcoming data } \\
\text { from multi-facility Duke costing study (see } \\
\text { Additional file } 1 \text { Section I, table } 8 \text { ) }\end{array}$ \\
\hline & $\begin{array}{l}\text { Inpatient OOP direct non-medical } \\
\text { costs per case }\end{array}$ & 4.16 & $\begin{array}{l}\text { Authors' calculation using forthcoming data } \\
\text { from multi-facility Duke costing study (see } \\
\text { Additional file } 1 \text { Section I, table 10) }\end{array}$ \\
\hline & $\begin{array}{l}\text { Inpatient OOP indirect costs per } \\
\text { case }\end{array}$ & $\begin{array}{l}2.98,4.75 \\
6.91,10.36 \\
19.26\end{array}$ & $\begin{array}{l}\text { Authors' calculation using data on daily } \\
\text { consumption and days spent caregiving from } \\
\text { [57], [58]. }\end{array}$ \\
\hline & $\begin{array}{l}\text { Outpatient cost of } \\
\text { implementation per case, ACTs } \\
\text { used }\end{array}$ & 10.50 & $\begin{array}{l}\text { Authors' calculation using estimates of OOP } \\
\text { expenditure as a percentage of total health } \\
\text { expenditure in Nigeria [43]. }\end{array}$ \\
\hline & $\begin{array}{l}\text { Outpatient cost of } \\
\text { implementation per case, non- } \\
\text { ACTs used }\end{array}$ & 8.28 & $\begin{array}{l}\text { Authors' calculation using estimates of OOP } \\
\text { expenditure as a percentage of total health } \\
\text { expenditure in Nigeria [43]. }\end{array}$ \\
\hline & $\begin{array}{l}\text { Inpatient cost of implementation } \\
\text { per case }\end{array}$ & 51.65 & $\begin{array}{l}\text { Authors' calculation using estimates of OOP } \\
\text { expenditure as a percentage of total health } \\
\text { expenditure in Nigeria [43]. }\end{array}$ \\
\hline & Nigeria GNI & 2030 & [59] \\
\hline & Nigeria Gini Index & 35.1 & {$[60]$} \\
\hline
\end{tabular}

\section{Results}

\section{Base case mortality and economic burden of under-five malaria in Nigeria}


In the base case scenario without intervention, the model estimated a total of 93,734 annual under-five malaria deaths, 8,637 annual individual cases of CHE, and US\$205,221,385 in annual OOP expenditure as a result of treating under-five malaria in Nigeria (Table 2 ). The poorest two quintiles accounted for $66 \%$ of mortality, $76 \%$ of $\mathrm{CHE}$, and $53 \%$ of OOP expenditure. Apart from quintile 1, cases of $\mathrm{CHE}$ were exclusively attributable to the cost of inpatient hospitalization.

Table 2

Base case annual under-five malaria health and economic indicators in Nigeria

\begin{tabular}{|llll|}
\hline Wealth quintile & Under-five deaths (thousands) & OOP expenditure (millions, US\$) & Cases of CHE (thousands) \\
\hline Q1 & 34.3 & 54.9 & 4.0 \\
\hline Q2 & 27.9 & 54.2 & 2.6 \\
\hline Q3 & 20.6 & 47.3 & 1.7 \\
\hline Q4 & 8.9 & 33.3 & 0.4 \\
\hline Q5 & 2.0 & 15.6 & 0 \\
\hline Total & 93.7 & 205.2 & 8.6 \\
\hline
\end{tabular}

\section{Deaths averted through interventions}

The $50 \%$ DMC, full DMC, and full DMC + NMC + IC subsidies respectively averted a total of about 4,500, 9,300, and 19,000 under-five deaths (Fig. 2). Across all intervention scenarios, health benefits were concentrated among the poor, with the poorest two quintiles accounting for $72 \%$ of all deaths averted and the richest quintile accounting for $1 \%$ of all deaths averted on average (see Additional file 1 Section VI, Fig. 1).

\section{OOP expenditure averted through interventions}

The 50\% DMC, full DMC, and full DMC + NMC + IC subsidies respectively averted a total of US\$70.1 million, US\$142.1 million, and US\$205.2 million in OOP expenditure across all quintiles (Fig. 3). In all intervention scenarios, benefits were concentrated among the poor, with the poorest two quintiles accounting for $55 \%$ and the richest quintile for accounting for $7 \%$ of total OOP expenditure averted on average (Additional file 1 Section VI, Fig. 2).

In terms of OOP expenditure averted, the incremental benefits across interventions were greater between the $50 \% \mathrm{DMC}$ and the full DMC subsidies than between the full DMC and full DMC + NMC + IC subsidies. On average across quintiles, the full DMC subsidy resulted in $202 \%$ more OOP expenditure averted than the $50 \%$ DMC subsidy, while the full DMC + NMC + IC subsidy resulted in 49\% more OOP expenditure averted than the full DMC subsidy (Fig. 4). The incremental economic benefits of the full DMC subsidy were marginally greater for the poor than the wealthy, while the incremental economic benefits of the full DMC + NMC + IC subsidy were much greater for the wealthy than the poor.

\section{Financial risk protection afforded through interventions}

The 50\% DMC, full DMC, and full DMC + NMC + IC subsidies respectively averted a total of 7,202, 8,604, and 8,637 annual cases of individual CHE (Fig. 5). Across all intervention scenarios, the poorest two quintiles accounted for $74 \%$ of all cases of CHE averted on average (Additional file 1 Section VI, Fig. 3), while quintile 5 experienced no CHE benefits. Only quintiles 1 and 2 experienced incremental benefits between the $50 \%$ DMC and the full DMC subsidies, with quintile 1 experiencing greater incremental benefits. Additionally, only quintile 1 experienced incremental benefits between the full DMC subsidy and the full DMC + NMC + IC subsidy, which were marginal.

\section{Cost of implementation}

The 50\% DMC, full DMC, and full DMC + NMC + IC subsidies would respectively cost the government US\$90.5 million, US\$179.1 million, and US\$254.4 million to implement over one year (Table 3 ). Across all intervention scenarios, the 
majority of expenditure would go toward treatment coverage for the poorest Nigerians, with the poorest two quintiles accounting for $56 \%$ of total intervention costs on average (Additional file 1 Section VI, Fig. 4).

Table 3

Cost of implementation (in millions, US\$)

\begin{tabular}{|lllllll|}
\hline Wealth quintile & Q1 & Q2 & Q3 & Q4 & Q5 & Total \\
\hline 50\% DMC subsidy & 25.7 & 24.7 & 20.4 & 13.9 & 5.8 & 90.5 \\
\hline Full DMC subsidy & 51.1 & 48.9 & 40.3 & 27.4 & 11.5 & 179.1 \\
\hline Full DMC + NMC + IC subsidy & 70.5 & 68.2 & 57.3 & 40.1 & 18.3 & 254.4 \\
\hline
\end{tabular}

\section{Targeted subsidies: benefits per US\$1 million invested in each quintile}

Per US\$1 million invested in each quintile, deaths and cases of CHE averted were greatest among the poor. For all interventions, investing US\$1 million into either of the bottom two quintiles would avert more deaths and cases of CHE than investing broadly across all quintiles. (Table 4 ). Per US\$1 million invested in each quintile, OOP expenditure averted would be relatively equitable in the intervention scenarios that do not subsidize nonmedical and indirect costs. However, for subsidies of nonmedical and indirect costs, wealthy quintiles would avert more OOP expenditure per dollar spent than poor quintiles.

Table 4

Benefits per US\$ 1 million invested in each quintile through targeted subsidies

\begin{tabular}{|c|c|c|c|c|c|c|c|c|c|}
\hline \multirow{2}{*}{$\begin{array}{l}\text { Scenario } \\
\text { Wealth } \\
\text { quintile }\end{array}$} & \multicolumn{3}{|c|}{$50 \%$ DMC subsidy } & \multicolumn{3}{|c|}{ Full DMC Subsidy } & \multicolumn{3}{|c|}{ Full DMC + NMC + IC Subsidy } \\
\hline & $\begin{array}{l}\text { Deaths } \\
\text { Averted }\end{array}$ & $\begin{array}{l}\text { Cases } \\
\text { of CHE } \\
\text { Averted }\end{array}$ & $\begin{array}{l}\text { OOP } \\
\text { expenditure } \\
\text { averted } \\
\text { (\$US) }\end{array}$ & $\begin{array}{l}\text { Deaths } \\
\text { Averted }\end{array}$ & $\begin{array}{l}\text { Cases } \\
\text { of CHE } \\
\text { Averted }\end{array}$ & $\begin{array}{l}\text { OOP } \\
\text { Expenditure } \\
\text { Averted } \\
\text { (SUS) }\end{array}$ & $\begin{array}{l}\text { Deaths } \\
\text { Averted }\end{array}$ & $\begin{array}{l}\text { Cases } \\
\text { of CHE } \\
\text { Averted }\end{array}$ & $\begin{array}{l}\text { OOP } \\
\text { Expenditure } \\
\text { Averted } \\
\text { (\$US) }\end{array}$ \\
\hline Q1 & 68 & 112 & 767068 & 78 & 77 & 786639 & 118 & 56 & 777721 \\
\hline Q2 & 55 & 91 & 773742 & 56 & 53 & 792114 & 88 & 38 & 794950 \\
\hline Q3 & 46 & 81 & 778850 & 42 & 41 & 798819 & 65 & 29 & 825721 \\
\hline Q4 & 26 & 29 & 780029 & 28 & 15 & 798075 & 28 & 10 & 829994 \\
\hline Q5 & 17 & 0 & 781625 & 10 & 0 & 794492 & 10 & 0 & 851721 \\
\hline $\begin{array}{l}\text { All } \\
\text { quintiles } \\
\text { (broad } \\
\text { subsidy) }\end{array}$ & 50 & 80 & 774472 & 52 & 48 & 793126 & 76 & 34 & 806708 \\
\hline
\end{tabular}

\section{Sensitivity Analysis}

When changed by $20 \%$, the most impactful model parameters on all ECEA outcomes on average were (1) the total number of annual under-five malaria cases and (2) initial treatment coverage, (average effect sizes of $21 \%$ and $24 \%$, respectively). The number of under-five deaths averted was particularly impacted by (1) the probability that an untreated case progresses to severe and (2) the case fatality rate of untreated severe cases (with effect sizes of $19 \%$ and $17 \%$, respectively). OOP expenditure averted was more impacted by uncertainty in outpatient costs than inpatient costs, and uncertainty in direct medical costs was more impactful than uncertainty in nonmedical and indirect costs (effect sizes of $5 \%$ and $1 \%$, respectively for outpatient and inpatient direct medical costs). The most impactful parameter on cases of $\mathrm{CHE}$ averted was inpatient direct medical cost (effect size of 40\%). The cost of implementation was substantially more impacted by uncertainty in the costs of outpatient care than inpatient care (effect sizes of $10 \%$ and $1 \%$, respectively). A summary of all sensitivity analysis results for all parameters is reported in the Additional file 1 Sections VII. 


\section{Discussion}

We used extended cost-effectiveness analysis (ECEA) to estimate the health and economic effects of subsidizing case management of under-five malaria in Nigeria. Our model estimates 93,734 annual under-five malaria deaths in a baseline, non-intervention scenario, $66 \%$ of which are attributable to the poorest $40 \%$ of children (Table 2 ). Estimated baseline mortality is comparable to figures reported by the WHO Severe Malaria Observatory and the IHME Global Burden of Disease database, which both report about 95,000 annual under-five malaria deaths in Nigeria [42, 44]. Our model also estimates that Nigerians spend over US\$200 million annually on case management of under-five malaria and that $53 \%$ of this cost is incurred by the poorest $40 \%$ of Nigerians. This is a sizeable proportion of the reported US\$700 million in annual OOP spending on malaria treatment, prevention, and other costs across all ages [1]. Our model estimates that this high OOP expenditure results in over 8,600 annual individual cases of catastrophic health expenditure (CHE), 76\% of which are concentrated among the poorest $40 \%$ of Nigerians (Table 2 ). These results emphasize the extent of child health inequity in Nigeria, stressing the need to employ an equity-focused approach to health policymaking that targets the poorest and most underserved populations rather than the mainstream, one-size-fits-all approach that may inadvertently favor the wealthy [26, 29]. This is especially important in light of recent plateaus in donor funding of malaria control programs, which may limit the scale of government interventions $[35,45]$.

Our analysis is one of the first ECEAs of under-five malaria and to our knowledge the first to investigate how the effects of any health intervention in Nigeria would be distributed across socioeconomic lines. A recent ECEA of malaria interventions in Ethiopia found that scaling up coverage of ACTs would afford the greatest health benefits and financial risk protection relative to scaling up use of indoor residual spray, insecticide-treated bed nets, and a hypothetical vaccine [22]. Consistent with our own analysis, this study also found that the health and economic benefits of a treatment subsidy would be concentrated among the poor. Another ECEA found that compared to other interventions in Ethiopia, such as those addressing childhood diarrhea and pneumonia, malaria interventions would see modest benefits, but this is likely due to the relatively low malaria burden in Ethiopia $[46,47]$. Our analysis builds on the exiting body of ECEA evidence for malaria interventions in Sub-Saharan Africa by investigating different financing strategies that account for nonmedical and indirect costs and expanding geographic scope to Nigeria, the most malaria-burdened country in the world [1].

\section{Effects of broad subsidies}

Larger case management subsidies would generally result in greater health and economic benefits. (Figs. 2,3,5). The full DMC + NMC + IC subsidy, which averted 76 deaths per US\$1 million invested broadly across all wealth groups, resulted in substantially greater health benefits than the full DMC and 50\% DMC subsidies, which respectively averted 52 and 50 deaths per US\$1 million invested across all wealth groups (Table 4 ). Across intervention scenarios, benefits would be concentrated among the poor, with the poorest $40 \%$ of children accounting for $72 \%$ of deaths averted, $55 \%$ of OOP expenditure averted, and $74 \%$ of all cases of CHE averted on average (Additional file 1 Section VI, Figs. 1-3).

While a full DMC + NMC + IC subsidy would avert US\$63.1 million more OOP expenditure than a full DMC subsidy, we found almost no difference in incremental cases of CHE averted between the two scenarios. In other words, financial risk protection benefits are limited to subsidizing direct medical costs of treatment. Resultingly, a full DMC + NMC + IC subsidy would avert 34 cases of CHE per US\$1 million invested broadly, compared to 48 cases averted in the full DMC scenario and 80 cases averted in the $50 \%$ DMC scenario (Table 4 ). While non-medical and indirect costs may not be catastrophic, compensating caregivers for these costs may still incentivize care-seeking because individuals in Nigeria often experience multiple different health problems in a given year (acute respiratory infection, pneumonia, HIV/AIDS, etc.), and the cumulative nonmedical and indirect costs could be catastrophic [48].

\section{Effects of targeted subsidies}


Subsidies targeted to the poor would avert more deaths per dollar spent than non-targeted subsidies applied broadly across wealth groups. For example, in the full DMC + NMC + IC scenario, US\$1 million invested into the poorest fifth of Nigerians would avert 118 deaths, while US\$1 million invested broadly would avert 76 deaths, and US\$1 million invested into the richest fifth would avert 10 deaths (Table 4 ). Furthermore, subsidies targeted to the poor would afford more financial risk protection per dollar spent than broad subsidies; in the full DMC + NMC + IC scenario, for example, investing US\$1 million into the poorest fifth of Nigerians would avert 56 cases of $\mathrm{CHE}$, compared to 34 cases averted if invested broadly and 0 cases averted if invested into the richest fifth (Table 4 ).

While targeted subsidies of direct medical costs would result in relatively equitable OOP savings across wealth groups, targeted subsidies of nonmedical and indirect costs would result in relatively more OOP savings for the wealthy (Fig. 4, Table 4 ). For example, in the full DMC + NMC + IC scenario, the wealthiest fifth of Nigerians would save about US\$850,000 per US\$1 million invested while the poorest fifth would save about US\$780,000 per US\$1 million invested (Table 4 ). This is likely because higher income individuals incur higher indirect costs on account of productive time lost to caring for sick children-however, these costs are less likely to be catastrophic with increasing wealth [36].

\section{Limitations}

Since our decision tree model is static, we assume that the case load of malaria would remain the same across the duration of the intervention course [49]. This assumption does not mirror the realities of transmissible diseases like malaria, but the dynamics of malarial transmission are unlikely to change significantly within a year of implementation, which is the projected time frame of the scenarios we modelled. Furthermore, effective treatment has been shown to interrupt malaria transmission, so this policy could potentially move Nigeria closer to malaria elimination and lower costs in future years [50, 51]. Second, our model assumes that case management of uncomplicated malaria incurs outpatient health facility costs, but uncomplicated malaria is often treated in community settings in Nigeria [16]. The likely impact of this assumption is an overestimation of total OOP expenditure averted and total cost of implementation. Estimates of total financial risk protection, however, are relatively unaffected by this assumption because in our model, CHE is most impacted by the cost of severe malaria cases requiring inpatient hospitalization (see Additional file 1 Section VII, Table 1). Third and most significantly, our methodology approximates initial treatment coverage rates as care-seeking behavior for febrile under-fives, a common assumption made in modelling studies of malaria-endemic countries [22]. However, the etiology of under-five fever can also include infection with HIV/AIDS, acute respiratory infection, anemia and pneumonia, so care-seeking for febrile under-fives may not reflect the true coverage rate for malaria treatment [48]. Initial treatment coverage is one of the most influential variables in our model for estimation of all ECEA outcomes (average effect size of $24 \%$ when changed by $20 \%$ ), so this is a key limitation (Additional file 1 Section VII, Table 1).

\section{Conclusions}

Under-five malaria in Nigeria remains one of the biggest challenges to global child health. Stark health inequities between the rich and the poor necessitate the introduction of targeted interventions that benefit the most vulnerable. Targeted subsidization of case management of under-five malaria may be a pro-poor intervention that leads to significant reductions in national under-five mortality and illness-related impoverishment, contributing progress to several of the Sustainable Development Goals including reducing poverty (SDG 1), ensuring good health and well-being at all ages (SDG 3), and reducing inequality within societies (SDG 10). This study provides context for future research that may inform possible policy recommendations. For example, while our study estimates the costs and benefits of subsidizing case management of under-five malaria, a budget impact analysis should be done to determine whether Nigeria can afford such a policy. Furthermore, if case management subsidies are introduced into Nigeria's Basic Healthcare Provision Fund (BHCPF), an actuarial analysis should be done to understand how the BHCPF would be impacted. Finally, this study provides groundwork for economic inequality analysis of other potential interventions deployed in a low- and middle-income country context.

\section{Abbreviations}

Page $12 / 20$ 
ACT, artemisinin-based combination therapy; APCR, adequate parasitological and clinical response; CFR, case fatality rate; $\mathrm{CHE}$, catastrophic health expenditure; DHS, demographic and health survey; DMC, direct medical costs; ECEA, extended cost-effectiveness analysis; FMCHP, Free Maternal and Child Health Program; IC, indirect costs; IHME, Institute for Health Metrics and Evaluation; MDGs, Millennium Development Goals; NMC, nonmedical costs; OOP, out-of-pocket; SDGs, Sustainable Development Goals; UHC, universal health coverage; USD, United States Dollar

\section{Declarations}

- Ethics approval and consent to participate: n/a (no human subjects)

- Consent to publish: n/a (no human subjects)

- Availability of data and materials: the demographic and epidemiological data that support the findings of this study are available from the Nigeria Demographic and Health Survey, https://dhsprogram.com/publications/publicationfr359-dhs-final-reports.cfm

- Competing interests: The authors declare that they have no competing interests

- Funding: RD received funding from the Department of Science and Society at Duke University through the Huang Fellowship and the Duke-Margolis Center for Health Policy at Duke University to cover his time. RD also received funding for TreeAge software from North Carolina State University through the George T. Barthalmus Research Award. WM and $\mathrm{OO}$ were funded through Duke CPIGH's 4D transitions study in Nigeria supported by the Bill and Melinda Gates Foundation (OPP1199624) and the Partnership for Maternal Newborn and Child Health. The funders had no role in study design, data collection and analysis, decision to publish, or preparation of the manuscript.

- Author's contributions: OO, WM and RD conceived the study idea and design. RD performed all major analyses and was the major contributor to the manuscript. $\mathrm{OO}$ and WM contributed to manuscript revisions. All authors read and approved the final manuscript.

- Acknowledgements: The authors thank Ashwini Sunil Deshpande from the Duke Center for Policy Impact in Global Health for assistance in data extraction from the Nigeria Living Standard Survey, Gavin Yamey from the Duke Center for Policy Impact in Global Health for project support, and Megan Knauer from the Duke-Margolis Center for Health Policy for assistance with the TreeAge Pro Healthcare software.

\section{References}

1. World malaria report 2019. Licence: CC BY-NC-SA 3.0 IGO. Geneva: World Health Organization; 2019.

2. Global Technical Strategy for. Malaria 2016-2030. Geneva: World Health Organization; 2016.

3. World malaria report 2017. Licence: CC BY-NC-SA 3.0 IGO. Geneva: World Health Organization; 2017.

4. Fact Sheet about Malaria. World Health Organization, World Health Organization. 2020, . Accessed Dec 2020.

5. Onwujekwe O, Uguru N, Etiaba E, et al. The economic burden of malaria on households and the health system in Enugu State southeast Nigeria. PloS One 2013;8: e78362.https://doi.org/10.1371/journal.pone.0078362.

6. Beargie SM, Higgins CR, Evans DR, et al. The economic impact of substandard and falsified antimalarial medications in Nigeria. PLoS One. 2019;14(8):e0217910. https://doi.org/10.1371/journal. pone.0217910.

7. Edelu BO, Ndu IK, Igbokwe O, et al. Severe falciparum malaria in children in Enugu, South East Nigeria. Niger J Clin Pract. 2018;21:1349-55.

8. United States Embassy in Nigeria. Nigeria Malaria Fact Sheet; 2011. Retrieved from https://photos.state.gov/libraries/nigeria/231771/Public/December-MalariaFactSheet2.pdf. Accessed Dec 2020.

9. United States Embassy in Nigeria, Nigeria Malaria Fact Sheet; 2013. Retrieved from http://photos.state.gov/libraries/nigeria/231771/Public/December-MalariaFactSheet2.pdf. Accessed Dec 2020.

Page $13 / 20$ 
10. Adewemimo A, Kalter HD, Perin J, et al. Direct estimates of cause-specific mortality fractions and rates of under-five deaths in the northern and southern regions of Nigeria by verbal autopsy interview. PLoS One. 2017;12(5):e0178129. https://doi.org/10.1371/journal.pone.0178129.

11. Uneke C, Sombie I, Uro-Chukwu H, et al. Developing equity-focused interventions for maternal and child health in Nigeria: an evidence synthesis for policy, based on equitable impact sensitive tool (EQUIST). Pan Afr Med J. 2019;34:158. doi:10.11604/pamj.2019.34.158.16622.

12. Ezenduka C, Falleiros D, Godman B. Evaluating the Treatment Costs for Uncomplicated Malaria at a Public Healthcare Facility in Nigeria and the Implications. Pharmacoecon Open. 2013;1(3):185-94. https://doi.org/10.1007/s41669-0170021-8.

13. Bhutta Z, Black R. Global maternal, newborn, and child health-so near and yet so far. N Engl J Med. 2013;369(23):2226-35.

14. Thwing J, Eisele T, Steketee R. Protective efficacy of malaria case management for preventing malaria mortality in children: a systematic review for the Lives Saved Tool. BMC Public Health, 2011;11(3).doi:10.1186/1471-2458-11-S3S14.

15. O'Connell K, Gatakaa H, Poyer S, et al. Got ACTs? Availability, price, market share and provider knowledge of antimalarial medicines in public and private sector outlets in six malaria-endemic countries. Malar J. 2010;10:326. https://doi.org/10.1186/1475-2875-10-326.

16. National Population Commission - NPC/Nigeria and ICF. Nigeria Demographic and Health Survey 2018. Abuja, Nigeria, and Rockville. Maryland: NPC and ICF; 2019.

17. Kumar S, Kumar N, Vivekadhish S. Millennium Development Goals (MDGs) to Sustainable Development Goals (SDGs): Addressing Unfinished Agenda and Strengthening Sustainable Development and Partnership. Indian J Community Med. 2016;41(1):,1-4. https://doi.org/10.4103/0970-0218.170955\.

18. Onwujekwe O, Obi F, Ichoku $\mathrm{H}$, Ezumah $\mathrm{N}$, et al. Assessment of a free maternal and child health program and the prospects for program re-activation and scale-up using a new health fund in Nigeria. Niger J Clin Pract. 2019;22:151629.

19. Ogbuabor D, Onwujekwe O. Implementation of free maternal and child healthcare policies: assessment of influence of context and institutional capacity of health facilities in South-east Nigeria. Glob Health Action. 2018;11(1):1535031. https://doi.org/10.1080/16549716.2018.1535031.

20. Onwujekwe O, Hanson K, Uzochukwu B, et al. Are malaria treatment expenditures catastrophic to different socioeconomic and geographic groups and how do they cope with payment? A study in southeast Nigeria. Trop Med Int Health. 2010 Jan;15(1):18-25. doi:10.1111/j.1365-3156.2009.02418.x.

21. Acharya S, Lin V, Dhingra N. The role of health in achieving the sustainable development goals. Bull World Health Organ. 2018;96(9):591-1A. https://doi.org/10.2471/BLT.18.221432.

22. Assebe L, Kwete XJ, Wang D, et al. Health gains and financial risk protection afforded by public financing of selected malaria interventions in Ethiopia: an extended cost-effectiveness analysis. Malar $\mathrm{J}$ 2020;19,41.https://doi.org/10.1186/s12936-020-3103-5.

23. Verguet $S$, Woldemariam AT, Durrett WN, et al. Is the sustainable development goal target for financial risk protection in health realistic? BMJ Glob Health. 2017;2(3):e000216. doi:10.1136/bmjgh-2016-000216.

24. WHO. (n.d.). Sustainable Development Goals. Retrieved December 14. 2020, from https://www.who.int/healthtopics/sustainable-development-goals Accessed Dec 2020.

25. Abiiro GA, De Allegri M. Universal health coverage from multiple perspectives: a synthesis of conceptual literature and global debates. BMC Int Health Hum Rights 2015;15,17.https://doi.org/10.1186/s12914-015-0056-9.

26. White MT, Conteh L, Cibulskis R, et al. Costs and cost-effectiveness of malaria control interventions - a systematic review. Malar J. 2010;10:337. https://doi.org/10.1186/1475-2875-10-337.

Page $14 / 20$ 
27. UNICEF. Narrowing the Gaps: The power of investing in the poorest children. 2017. Retrieved from https://www.equist.info/files/general_files/GLB_3418glb-9355narrowing-the-gaps-2017.pdf. Accessed Nov 2020.

28. Waters $\mathrm{D}$, Theodoratou $\mathrm{E}$, Campbell $\mathrm{H}$, et al. Optimizing community case management strategies to achieve equitable reduction of childhood pneumonia mortality: An application of Equitable Impact Sensitive Tool (EQUIST) in five lowand middle-income countries. J Glob Health. 2012;2(2):,020402. https://doi.org/10.7189/jogh.02.020402.

29. Chao F, You D, Pedersen J, et al. National and regional under-5 morality rate by economic status for low-income and middle-income countries: a systematic assessment. Lancet 2018;(6),e535-547.

30. Carrera C, Azrack A, Begkoyian G, et al. The comparative cost-effectiveness of an equity-focused approach to child survival, health, and nutrition: a modelling approach. Lancet. 2012;380(9850):1341-51.

31. Verguet S, Kim J, Jamison D. Extended Cost-Effectiveness Analysis for Health Policy Assessment: A Tutorial. Pharmacoeconomics. 2016;34:913-23. doi:10.1007/s40273-016-0414-z.

32. Scott N, Hussain SA, Martin-Hughes R, et al. Maximizing the impact of malaria funding through allocative efficiency: using the right interventions in the right locations. Malar J. 2017;16:368. https://doi.org/10.1186/s12936-017-2019-1.

33. Houben $\mathrm{CH}$, Fleischmann $\mathrm{H}$, Gückel M. Malaria prevalence in north-eastern Nigeria: a cross-sectional study. Asian Pac J Trop Med. 2013;6(11):865-8. DOI:10.1016/s1995-7645(13)60154-6.

34. Hailu A, Lindtjørn B, Deressa W, et al. Economic burden of malaria and predictors of cost variability to rural households in south-central Ethiopia. PloS One. 2017;12(10):e0185315. https://doi.org/10.1371/journal.pone.0185315.

35. Arrow KJ, Panosian C, Gelband H, editors. The Human and Economic Burden of Malaria. In:Institute of Medicine (US) Committee on the Economics of Antimalarial Drugs. Saving Lives, Buying Time: Economics of Malaria Drugs in an Age of Resistance. Washington (DC): National Academies Press (US); 2004. Available from:

https://www.ncbi.nlm.nih.gov/books/NBK215634/.

36. El-Houderi A, Constantin J, Castelnuovo, et al. Economic and Resource Use Associated With Management of Malaria in Children Aged < 5 Years in Sub-Saharan Africa: A Systematic Literature Review. MDM Policy Pract. 2019.

DOI:10.1177/2381468319893986.

37. Cohen JL, Yadav P, Moucheraud C, et al. Do price subsidies on artemisinin combination therapy for malaria increase household use? Evidence from a repeated cross-sectional study in remote regions of Tanzania. PloS One. 2019;8(7):e70713. https://doi.org/10.1371/journal.pone.0070713.

38. U.S. President's Malaria Initiative Nigeria Malaria Operational Plan FY. 2020. Retrieved from (www.pmi.gov). Accessed Dec 2020.

39. Stresman G, Sepúlveda N, Fornace K, et al. Association between the proportion of Plasmodium falciparum and Plasmodium vivax infections detected by passive surveillance and the magnitude of the asymptomatic reservoir in the community: a pooled analysis of paired health facility and community data. Lancet Infect Dis. 2020;20(8):953-63. https://doi.org/10.1016/S1473-3099(20)30059-1.

40. Yakasai A, Hamza M, Dalhat M, et al. Adherence to Artemisinin-Based Combination Therapy for the Treatment of Uncomplicated Malaria: A Systematic Review and Meta-Analysis. J Trop Med. 2015.

2015.https://doi.org/10.1155/2015/189232.

41. Antony HA, Parija SC. Antimalarial drug resistance: An overview. Trop Parasitol. 2016;6(1):30-41. https://doi.org/10.4103/2229-5070.175081.

42. IHME GBD Results Tool. (2019). Retrieved from http://ghdx.healthdata.org/gbd-results-tool. Accessed Nov 2020.

43. Aregbeshola BS, Khan SM. Out-of-pocket health-care spending and its determinants among households in Nigeria: a national study. J Public Health (Berl. 2020. https://doi.org/10.1007/s10389-020-01199-x.

44. Nigeria severe malaria facts. (2020). Retrieved from https://www.severemalaria.org/countries/nigeria. Accessed Nov 2020. 
45. Korenromp E, Mahiané G, Hamilton M, et al. Malaria intervention scale-up in Africa: effectiveness predictions for health programme planning tools, based on dynamic transmission modelling. Malar J 2016;15,417.https://doi.org/10.1186/s12936-016-1461-9.

46. Pecenka CJ, Johansson KA, Memirie ST, et al. Health gains and financial risk protection: an extended costeffectiveness analysis of treatment and prevention of diarrhoea in Ethiopia. BMJ Open. 2015;5:e006402.

47. Verguet S, Olson ZD, Babigumira JB, et al. Health gains and financial risk protection afforded by public financing of selected interventions in Ethiopia: an extended cost-effectiveness analysis. Lancet Glob Health. 2015;3:e288-96.

48. Enya V, Idika N, Mafe AG, et al. Aetiology of fever among under fives in Lagos, Nigeria. BMC Infect Dis, 2014;14(Suppl 2),P42.https://doi.org/10.1186/1471-2334-14-S2-P42.

49. Lugnér AK, Mylius SD, Wallinga J. Dynamic versus static models in cost-effectiveness analyses of anti-viral drug therapy to mitigate an influenza pandemic. Health Econ 2010;19(5):518 - 31.doi:10.1002/hec.1485. PMID: 19382106.

50. White NJ. The role of anti-malarial drugs in eliminating malaria. Malar J 2008;11;7 Suppl 1(Suppl

1):S8.doi:10.1186/1475-2875-7-S1-S8.

51. Guidelines for the Treatment of Malaria. 3rd edition. Geneva: World Health Organization; 2015. Annex 2, Malaria transmission and antimalarial medicines. Retrieved from: https://www.ncbi.nlm.nih.gov/books/NBK294437/.

52. Lubell Y, Staedke SG, Greenwood BM, et al. Likely health outcomes for untreated acute febrile illness in the tropics in decision and economic models; a Delphi survey. PloS one. 2011;6(2):e17439.

https://doi.org/10.1371/journal.pone.0017439.

53. Challenger JD, Bruxvoort K, Ghani AC, et al. Assessing the impact of imperfect adherence to artemether-lumefantrine on malaria treatment outcomes using within-host modelling. Nat Commun. 2017;8:1373.

54. Lubell Y, Dondorp A, Guerin PJ, et al. Artemisinin resistance-modelling the potential human and economic costs. Malar J. 2014;13:452. doi:10.1186/1475-2875-13-452.

55. Graham H, Bakare AA, Ayede Al, et al. Diagnosis of pneumonia and malaria in Nigerian hospitals: A prospective cohort study. Pediatr Pulmonol 2020;55(S1). doi:10.1002/ppul.24691.

56. Olliaro P. Mortality Associated with Severe Plasmodium falciparum Malaria Increases with Age. Clinical Infect Dis. 2008;47(2):158-60.

57. Nigeria National Bureau of Statistics (NBS). General Household Survey, Panel 2015-2016, Wave 3.

58. Hennessee I, Chinkhumba J, Briggs-Hagen M, et al. Household costs among patients hospitalized with malaria: evidence from a national survey in Malawi, 2012. Malar J 2017;16,395.https://doi.org/10.1186/s12936-017-2038-y.

59. The World Bank. (2020). Gini index (World Bank estimate). Retrieved from https://data.worldbank.org/indicator/SI.POV.GINI Accessed Dec 2020.

60. The World Bank. Nigeria. (2020). Retrieved from https://data.worldbank.org/country/NG Accessed Dec 2020.

\section{Figures}



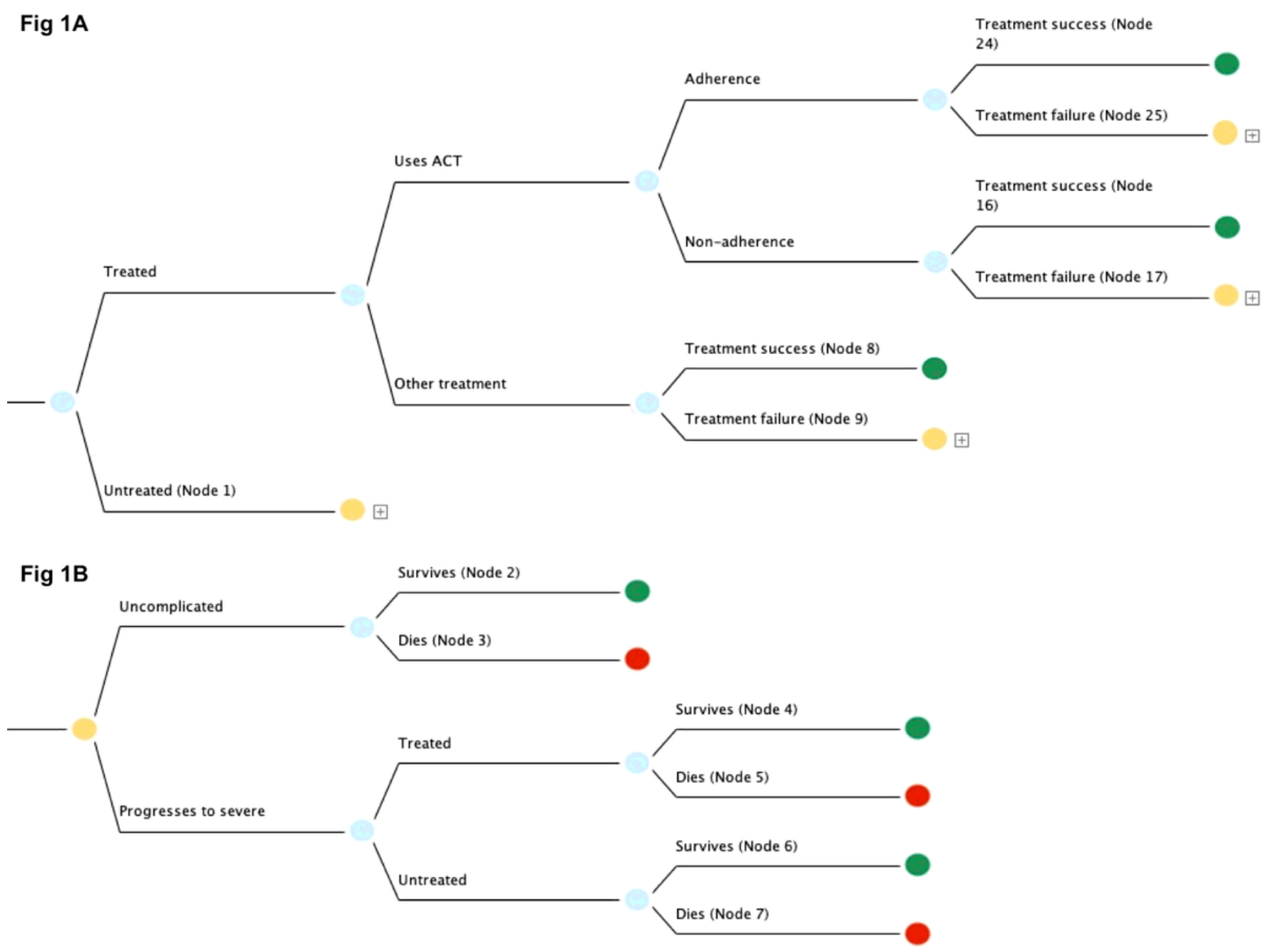

\section{Figure 1}

A: Decision tree used to model annual deaths and OOP expenditure associated with treating under-five malaria in Nigeria. 23 million annual cases were simulated. Identical trees were used for each wealth quintile (Q1-Q5) but with different parameters for costs, mortality, and case load. Green terminal nodes represent survival and orange nodes feed into subtrees representing cases that are either untreated or where treatment failure occurs, where disease prognosis may progress to severe (Nodes 1, 9, 17, and 25) B: Subtree modelling under-five malaria cases that are either untreated or where treatment failure occurs. Green and red terminal nodes respectively represent survival and death. 


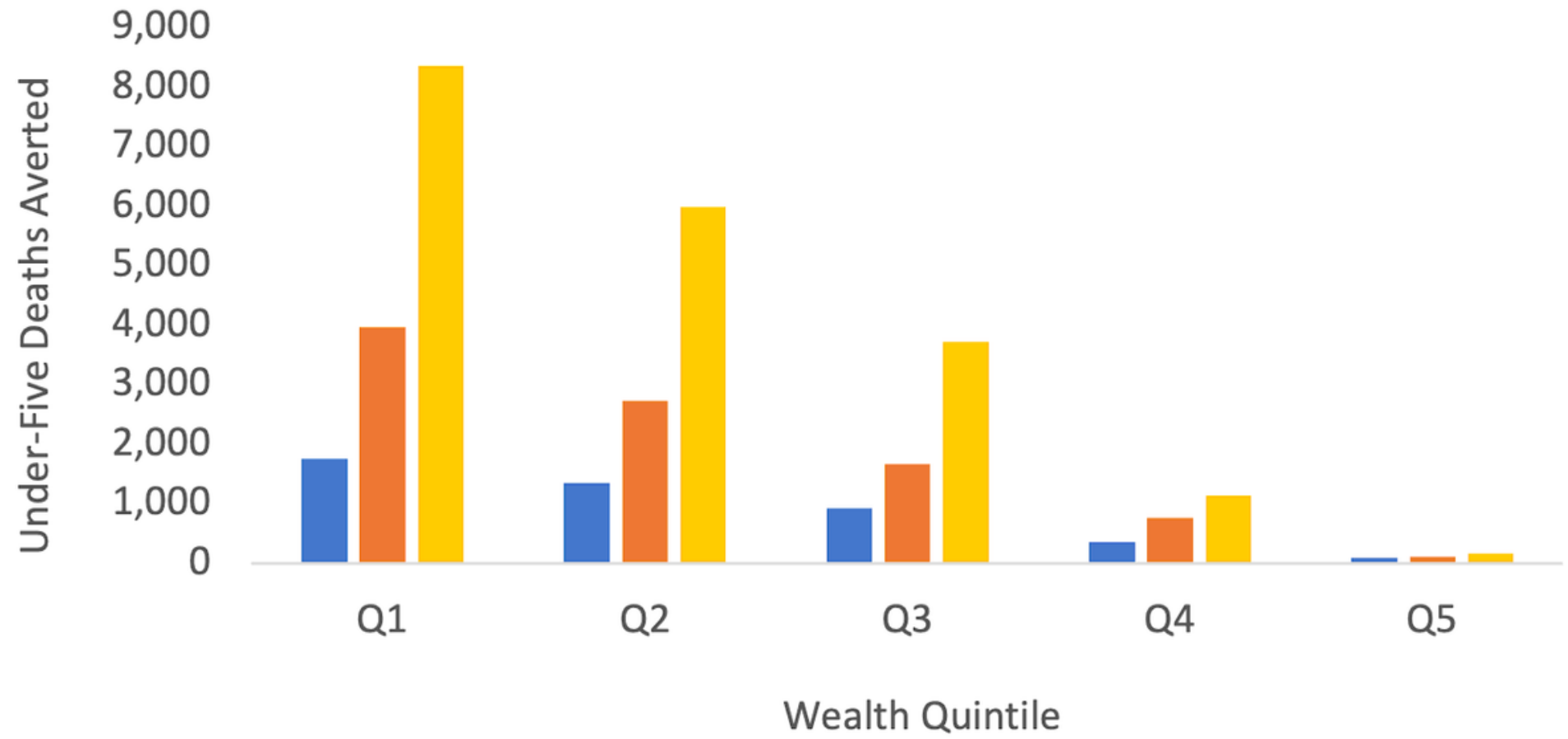

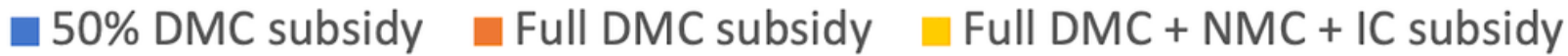

\section{Figure 2}

Annual under-five deaths averted through case management subsidies. Three different case management subsidies were modeled across socioeconomic lines. Deaths averted are concentrated among the poor.

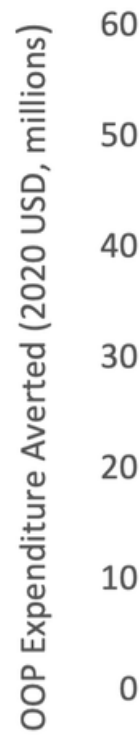

60

\section{0}

40

30

20

Q1

Q3

Wealth Quintile

घ0\% DMC subsidy $\quad$ Full DMC subsidy $\quad$ Full DMC + NMC + IC subsidy

Figure 3 
Annual OOP expenditure averted through case management subsidies. Three different case management subsidies were modeled across socioeconomic lines. OOP expenditure averted is concentrated among the poor.

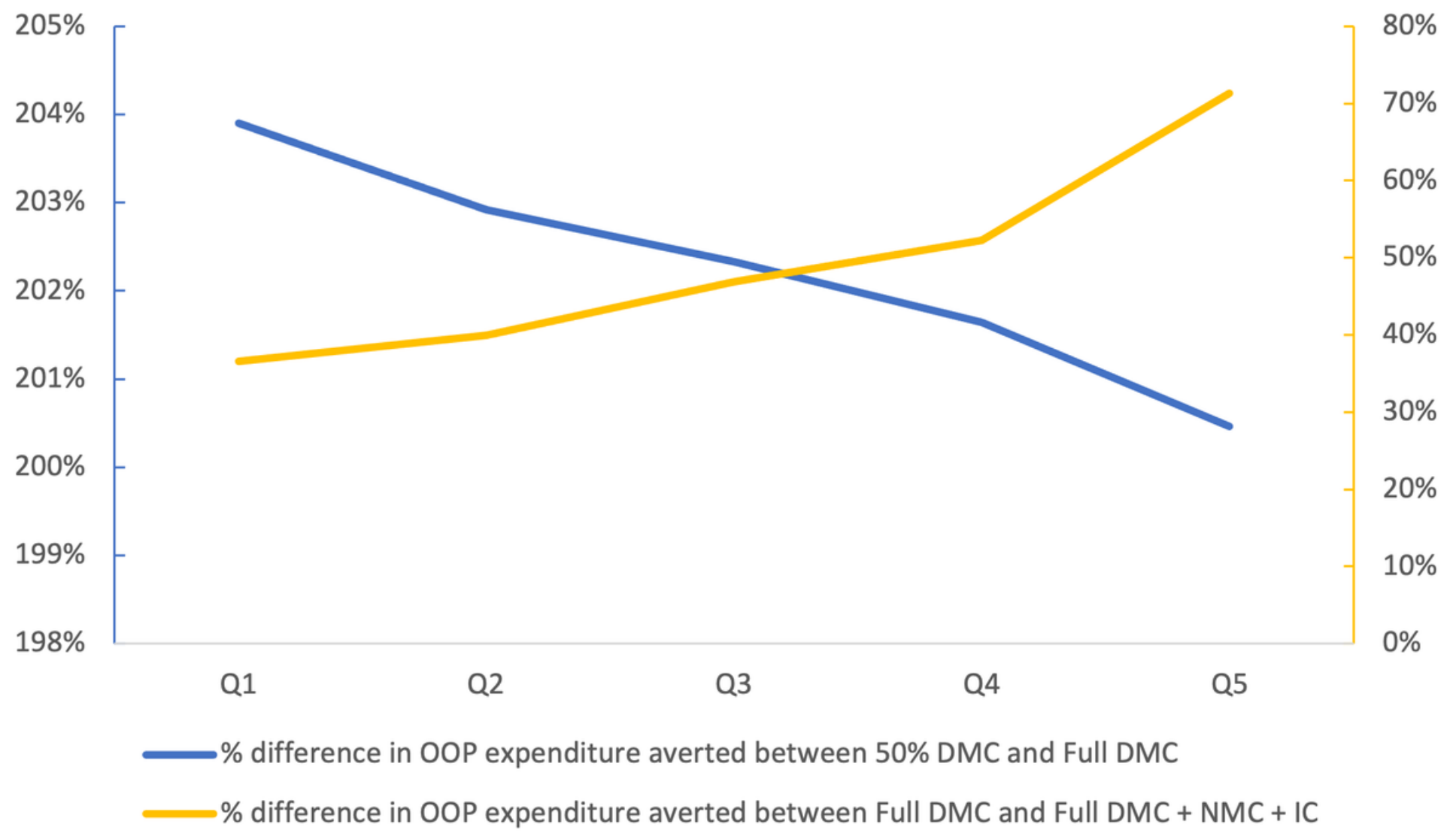

\section{Figure 4}

Incremental economic benefits of case management subsidies. For interventions subsidizing direct medical costs, incremental economic benefits are marginally greater for the poor than the wealthy (blue line). For interventions subsidizing nonmedical and indirect costs, incremental economic benefits are greater for the wealthy than the poor (yellow line). 


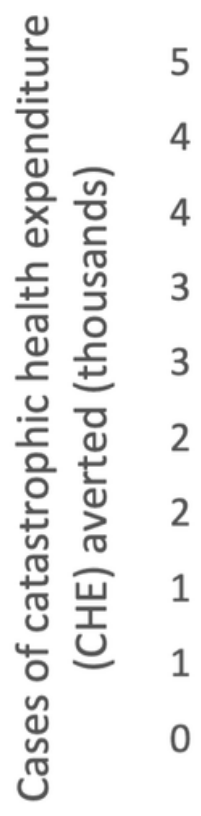

(1)

Q2

Q3

Q4

Wealth Quintile

50\% DMC subsidy

\section{Figure 5}

Annual financial risk protection afforded through case management subsidies. Annual under-five malaria related $\mathrm{CHE}$ averted by wealth quintile (Q1-Q5) in Nigeria by implementing three different interventions. CHE averted is concentrated among the poor.

\section{Supplementary Files}

This is a list of supplementary files associated with this preprint. Click to download.

- Additionalfile1.docx 